\title{
SPATIAL DISTRIBUTION OF CASTES WITHIN COLONIES OF THE TERMITE INCISITERMES SCHWARZI'
}

\author{
By Peter Luykx, Jack Michel, Jeannette K. LuykX ${ }^{2}$
}

\section{INTRODUCTION}

In order to describe the social organization of termites with any precision, it is essential to have quantitative information on the spatial distribution of castes within the colony. Such information is important not only for descriptive purposes, but also because it can give clues to the interactions that take place within and among the different castes.

Precise information on caste distribution within colonies is ordinarily not easy to obtain, because colonies are usually completely disrupted in opening them up, and because in any case the description of spatial organization in large three-dimensional or dispersed colonies in quantitative terms is difficult. But in some locations, colonies of certain kalotermitid species offer a unique opportunity to obtain just such data. In the Oleta River Mangrove Preserve just north of Miami, Florida, large numbers of Incisitermes schwarzi are found in slender, dead mangrove tree-trunks, where they form nearly one-dimensional colonies. Because the colonies are relatively small and are entirely above ground, and because the termites do not forage outside the wood, whole colonies can be collected in segments and analyzed. The results of such an analysis are the subject of this paper.

While some of the findings of this study - the association of larvae with the royal pair, the aggregation of nymphs and alates-have been noted before in a casual way in the general descriptions of many other students of the Isoptera (e.g., Imms, 1919; Grassé, 1949), this is the first quantitative description of the spatial distribution of castes in a termite, and is worth putting on record for that reason.

\footnotetext{
'This is contribution no. 245 from the Program in Tropical Biology, Ecology, and Behavior, Dept. of Biology, Univ. of Miami.

${ }^{2}$ Department of Biology, University of Miami, Coral Gables, FL 33124, U.S.A.

Manuscript received by the editor June 7, 1986
} 


\section{Materials AND Methods}

Colonies of Incisitermes schwarzi Banks (Kalotermitidae) were collected from the Oleta River Mangrove Preserve, North Miami Beach, Florida, on four collecting trips carried out between the hours of 9 a.m. and 12 noon, at low tide, during the months of March, April and May, 1985. (In this species, the annual reproductive cycles of different colonies are not synchronized, so that different reproductive stages may be found at any time of the year (Luykx, 1986).) Colonies of I. schwarzi were found only in standing trunks, not in fallen dead wood. Small, dead mangrove trees (Laguncularia racemosa) 3-4 $\mathrm{cm}$ in diameter and 1-3 $\mathrm{m}$ tall were selected and quickly cut into $10-12 \mathrm{~cm}$ segments with a chain saw. To minimize the possibility of redistribution of the termites during the sectioning, the tree was not touched before the first cut was made; the first cut was made at ground level, and all subsequent cuts were made with the tree held horizontally (to prevent the vibration of the saw from shaking termites from one segment to a lower segment). Complete sectioning of each tree was accomplished with 60-90 seconds of the first cut. We estimate we might have killed about $5 \%$ of the termites in each colony with the saw.

If a dead tree had termites (about half the ones chosen did), the segments were put into numbered plastic bags and taken back to the laboratory for opening and analysis. Determination of the sex and caste of each individual in each segment was usually carried out within one day of collection. We obtained useful data on a total of 9 complete colonies.

For the purpose of this analysis, seven castes were distinguished: larvae (the first three instars), workers (or pseudergates: later instars, with wing buds not readily seen with the naked eye), earlyand late-stage nymphs (the last two pre-imaginal molts, with elongated wing pads easily seen with the naked eye), alates (imagos), soldiers (small and large), and reproductives (king and queen). In the Kalotermitidae, the larvae, workers, nymphs, and alates represent a developmental series; the only truly sterile castes are the soldiers.

Males and females occur in all castes, with typically a slight excess of males among the soldiers and among the nymphs (Luykx, 1987). Except for a slight statistical tendency for soldiers of one sex to be associated with non-soldiers of the opposite sex, the sexes within the 
colonies were distributed essentially at random (Luykx et al., 1987), and will not be further considered here.

\section{Results AND CONCLUSIONS}

The distribution of the castes in nine pieces of wood is represented in Fig. 1. In eight of the nine pieces a single colony was found. In one piece two colonies were found: PL487, and a small incipient colony consisting only of the royal pair, one soldier, one larva, and five workers. This small colony, PL488, contained entirely within a single short segment, does not, of course, give any information on caste distribution, and will not be considered further.

The major portion of most of the colonies (with the exception of PL476 and PL486) was found toward the bottom, where the wood was less deteriorated and less fragile. (The topmost portions of the dead trunks are often thoroughly tunneled and in a highly deteriorated condition, and rarely contain any termites.) In most colonies, the king and queen were found together in the lower part of the colony (Fig. 2). It seems likely that the royal pair might initiate the colony at any level in suitable dead wood, but then move down into sounder wood as the colony grows.

Larvae (the first two or three instars) were found preferentially in the same segments as the royal pairs. As illustrated in Fig. 2, among the segments with reproductives, 7 out of 9 had more larvae than expected for those segments. Twelve of the 14 segments with more larvae than expected also had a reproductive or was adjacent to one that did. That this is a real association, and not just a common tendency for both larvae and reproductives to be located in the lower parts of the colony, is suggested by colony PL476, the one colony in which the reproductives were found in a segment in the upper part of the colony: in this colony the larvae also were concentrated in this same segment (Fig. 2).

The members of the different castes representing successive stages of development-workers, early-stage nymphs, late-stage nymphs and alates-showed successively greater degrees of aggregation. For example, when the cumulative proportions of workers, early-stage nymphs, and late-stage nymphs in colony PL482 are plotted separately as a function of the segment number in which they were found, it is apparent that the workers were distributed over a wider number of segments than the early-stage nymphs, and the early-stage 

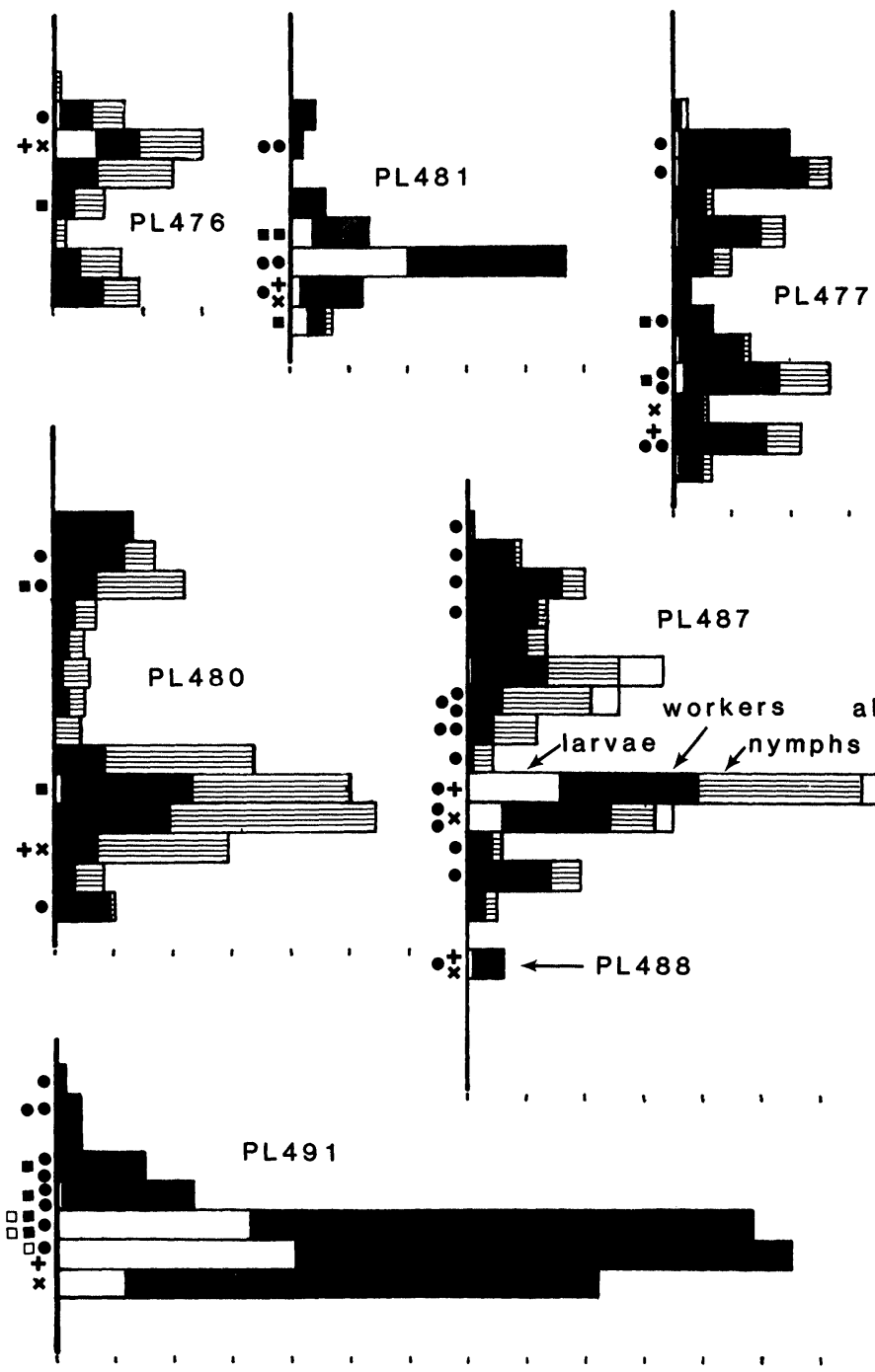

Fig. 1. Segment-by-segment distribution of castes in colonies contained in 9 pieces of wood. The base line indicates the height of the wood in each case. Represented on the left side of each colony are the numbers of individual soldiers (solid symbols) and presoldiers (open symbols)-circles, small soldiers and presoldiers; 

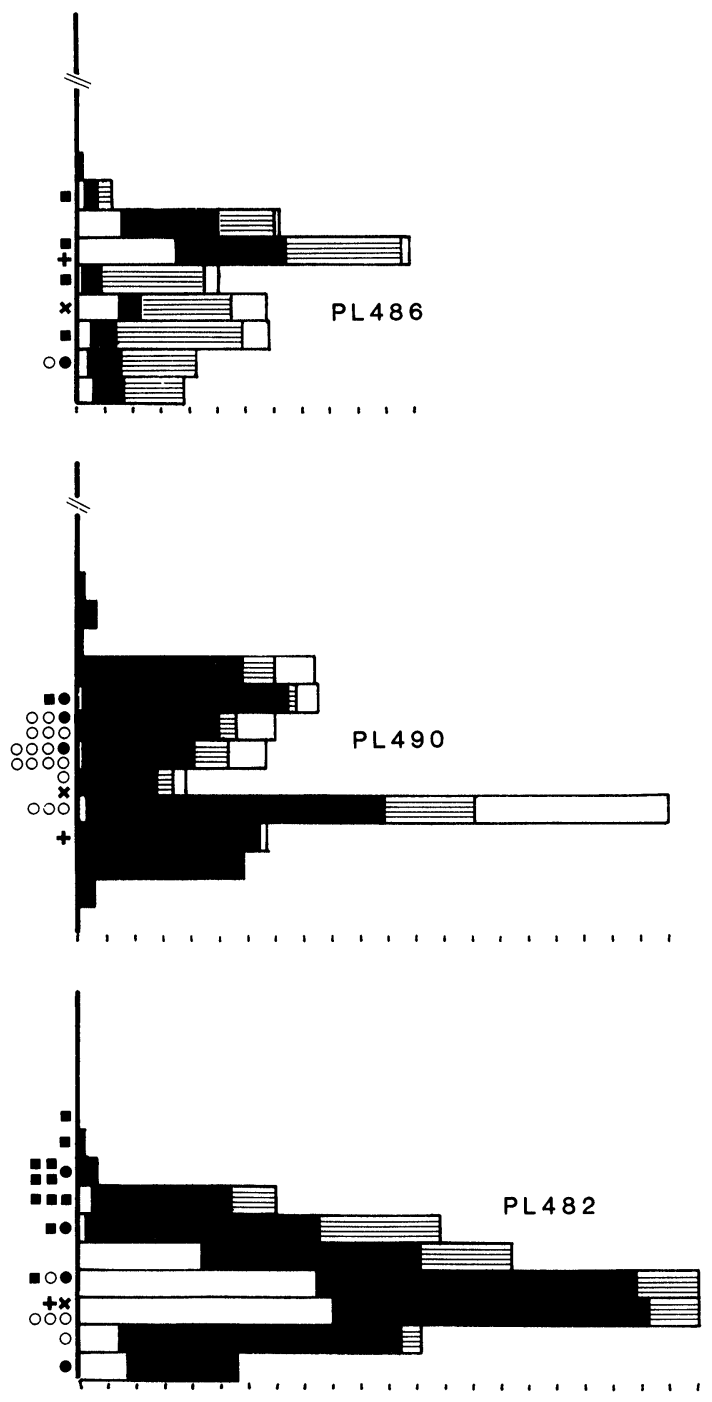

squares, large soldiers and presoldiers. Also shown are the reproductives,--+ , king; $X$, queen. See colony PL487 for legend for other castes. The space between successive tick-marks at the bottom of each colony represents ten individuals. Note that the scales for Figs. 1A and 1B are different. 


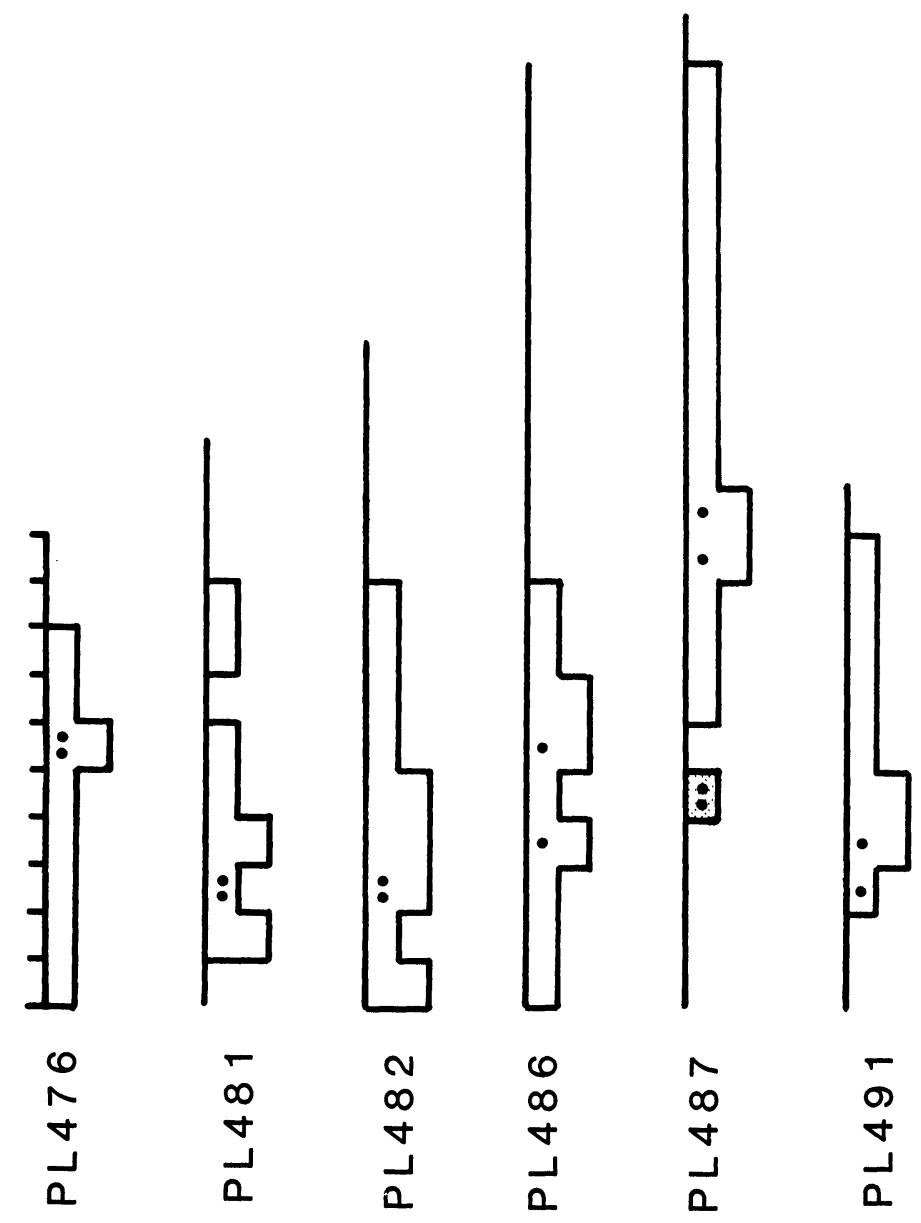

Fig. 2. Segment-by-segment distribution of larvae in relation to reproductives in 6 colonies (colonies PL477, PL480, and PL490 were omitted because they had too few larvae). The size of individual segments analyzed separately is indicated by the tick-marks on PL476. For each colony, the baseline alone indicates uninhabited wood; low boxes indicate fewer larvae, high boxes indicate more larvae than expected for that segment (based on the average number of larvae per segment for that colony). Dots represent reproductives. The shaded segment represents PL488, an incipient colony contained entirely within a single segment. 
nymphs over a wider number of segments than the late-stage nymphs (Fig. 3). The variance in position of the members of a caste can be used as a measure of the dispersion or aggregation of that caste, and then compared with the position-variance for all the members of all the major castes of the colony taken together. In colony PL487, for example, the ratio of the caste variance to total colony variance was $1.30,0.80,0.52$, and 0.40 , for the workers, early-stage nymphs, late-stage nymphs, and alates, respectively. A summary of all variance ratios for all seven of the colonies with nymphs or alates is given in Fig. 4.

There was no regularity in the mean positions of the major castes in relation to each other nor in relation to the top or bottom of the colony. In several colonies (e.g., PL482, Fig. 3), the mean position of the nymphs was higher than that of the workers, but just as often the reverse was true. In colonies PL482 and PL487, the mean posiof the early-stage nymphs was between that of the workers and of the late-stage nymphs, but in colony PL486 it was below that of those two castes. Neither was the mean position of alates (in the three colonies that had alates) consistent in relation to that of the other major castes.

The mean position of the soldiers, however, with the exception of those in colony PL477, was always above that for the bulk of the colony (e.g., colony PL482, Fig. 1). This makes sense in terms of the function of soldiers in defending the colony, for the wood in the upper part of the colonies is generally more deteriorated than that lower down, and presumably more susceptible to invasion by predators.

Six of the 9 colonies-PL476, PL477, PL480, PL486, PL487, and PL490-had bimodal distributions (Fig. 1). There was no clear or consistent difference between the top and bottom groups in total numbers of termites nor in overall caste composition in any of these colonies. (The excess numbers of nymphs and alates in the bottom groups of PL480 and PL486 are probably a secondary effect of the tendency of these castes to clump together.)

\section{Discussion}

The association of larvae with the reproductives has been casually noted by many students of the Kalotermitidae, but has not been 



Fig. 3. Distribution of workers (w), early-stage nymphs (n), and late-stage nymphs $\left(\mathrm{n}^{\prime}\right)$ in colony PL482. The mean position and standard deviation of the distribution for each caste is indicated by the three lines at the top.

documented quantitatively until now. Certainly the larvae are mobile enough to disperse themselves more widely. Even in the laboratory, after the disruption of field-collected colonies in opening them up and transferring them to petri dishes, the larvae are often found later to have re-aggregated under one fragment of wood, often in association with the reproductives. The significance 


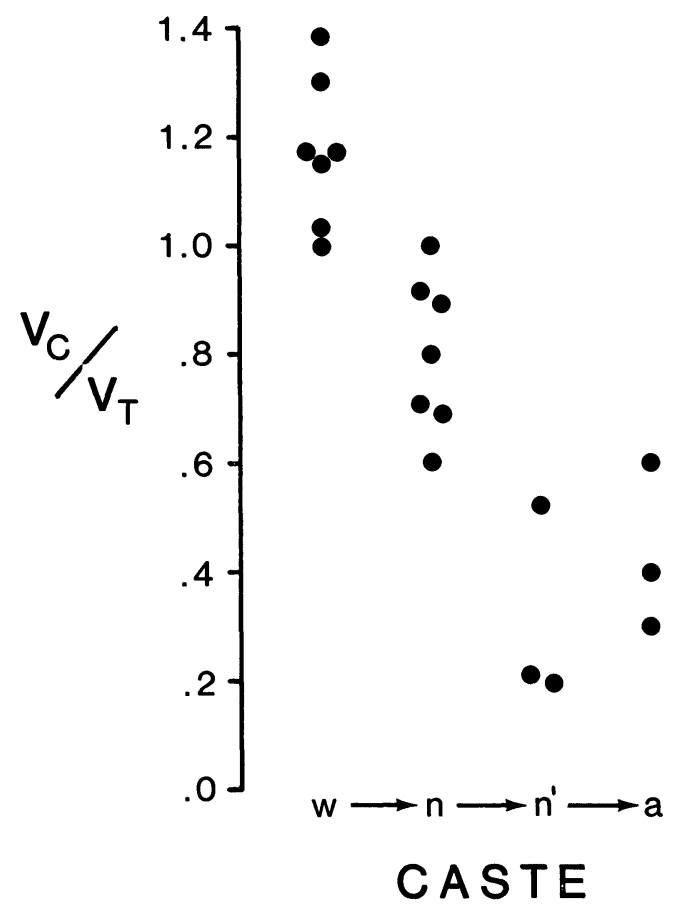

Fig. 4. Aggregation of individuals with successive developmental stage: w, workers; $n$, early-stage nymphs; $n^{\prime}$, late-stage nymphs; a, alates (imagos). $\mathrm{V}_{\mathrm{C}} / \mathrm{V}_{\mathrm{T}}$, ratio of position-variance of members of a given caste to position-variance of all castes in the colony taken together.

of the association is not entirely clear. It is usually thought (e.g., see Wilson, 1971) that in termites the care of the youngest larvae is assumed by older siblings - this is, after all, one of the hallmarks of eusociality. It might seem surprising, therefore, that the larvae remain associated with their parents even in the presence of numerous older siblings. It may be that in some termite species, particularly among the lower termites, the parents continue to provide some essential nutrients to newly-hatched larvae, something that cannot readily be provided by older siblings. Something like this has been seen by Nalepa (1984) in family groups in Cryptocercus punctulatus, a subsocial wood-eating cockroach widely regarded as a model of termite ancestors. 
Alternatively, the significance of the association between larvae and reproductives may be just the reverse: the larvae may be feeding the royal pair. What were classified as "larvae" in this study were approximately the first three instars. The newly hatched larvae, lacking intestinal flagellates, cannot feed themselves and therefore would not be expected to be able to feed other individuals either. But by the third instar the termites possess the intestinal symbionts, and can feed themselves. It may be that the younger instars (beyond the first or second) are responsible for the care of the reproductives. There is some evidence in other species of termites (reviewed by McMahan, 1979) that it is the younger workers that are primarily concerned with colony feeding functions, while older workers specialize in other acitivities.

These two alternatives could probably be distinguished by means of careful observations on the behavior of larvae and reproductives in laboratory colonies.

The aggregation of alates within the colony is interesting, and parallels laboratory observations on groups of alates removed from colonies. The aggregation may reflect a tendency of the alates to accumulate near an exit hole in preparation for emergence. The data in Fig. 4 demonstrate that the tendency to aggregate begins in the preceding nymphal stages. Buchli (1961) described an accumulation of late-stage nymphs and alates in the upper and peripheral regions of nests of Reticulitermes lucifugus, but this was apparently due to an antagonism between these stages and the main body of workers of the nest. In I. schwarzi nymphs and alates appear to aggregate in the main part of the colony without any mutual show of antagonism with other nestmates.

A striking feature of six of the nine colonies (PL476, PL477, PL480, PL486, PL487, and PL490) was a tendency for the termites to distribute themselves in the wood in two distinct groups. In general, the caste composition was about the same for the upper and lower groups (the excess of nymphs or alates in the bottom group in colonies PL480 and PL486 may simply be a secondary effect of the tendency of these castes to clump together). It seems unlikely, given the regular differences found in the distribution of the major castes, that this bimodal distribution is somehow an artefact of the procedure used in cutting the colony into segments with a consequent wholesale redistribution of members of the colony. It may be that as 
a colony grows, the wood in the center of the colony is often used up, and the members of the colony then spread upwards and downwards from the center.

\section{ACKNOWLEDGMENTS}

This work was supported by grant no. BSR-8119692 from the National Science Foundation. We are grateful to Dr. Steven Green for suggestions on how to evaluate the distribution of the major castes (Figs. 3 and 4), to Dr. Keith Waddington for comments on the manuscript, and to Carol A. Provost for help in preparing the figures.

\section{SUMMARY}

Nine colonies of the dry-wood termite Incisitermes schwarzi were rapidly cut into segments in the field, and the numbers of individuals of different castes in each segment analyzed in order to learn something about the distribution of castes within natural colonies. The main findings are that the royal pair is usually in the lower part of the colony, associated with small larvae; the mean position of soldiers is usually higher than the mean position for the whole colony; and, relative to the pseudergates, the early-stage nymphs, latestage nymphs, and alates are successively more clumped or aggregated within the colony.

\section{Literature Cited}

BuCHLI, $\mathrm{H}$.

1961. Les relations entre la colonie maternelle et les jeunes imagos ailés de Reticulitermes lucifugus. Vie et Milieu, 12: 627-632.

Grassé, P.-P.

1949. Ordre des isoptères ou termites. Traité de zoologie 9: 408-544. Masson, Paris.

IMms, A. D.

1919. On the structure and biology of Archotermopsis, together with descriptions of new species of intestinal protozoa, and general observations on the isoptera. Phil. Trans. Roy. Soc. Lond., B., 209: 75-180.

LUYKX, P.

1987. Termite colony dynamics as revealed by the sex- and caste-ratios of whole colonies of Incisitermes schwarzi Banks (Isoptera: Kalotermitidae). Insectes Sociaux (in press). 
LuYkx, P., J. Michael and J. K. LuYKX.

1987. The spatial distribution of the sexes in colonies of the termite Incisitermes schwarzi Banks (Isoptera: Kalotermitidae). Insectes Sociaux (in press).

MCMAHan, E. A.

1979. Temporal polyethism in termites. Sociobiology, 4: 153-168.

NALEPa, C. A.

1984. Colony composition, protozoan transfer and some life history charactristics of the woodroach Cryptocercus punctulatus Scudder (Dictyoptera: Cryptocercidae). Behav. Ecol. Sociobiol., 14: 273-279.

WILSON, E. O.

1971. The insect societies. Harvard Univ. Press. 

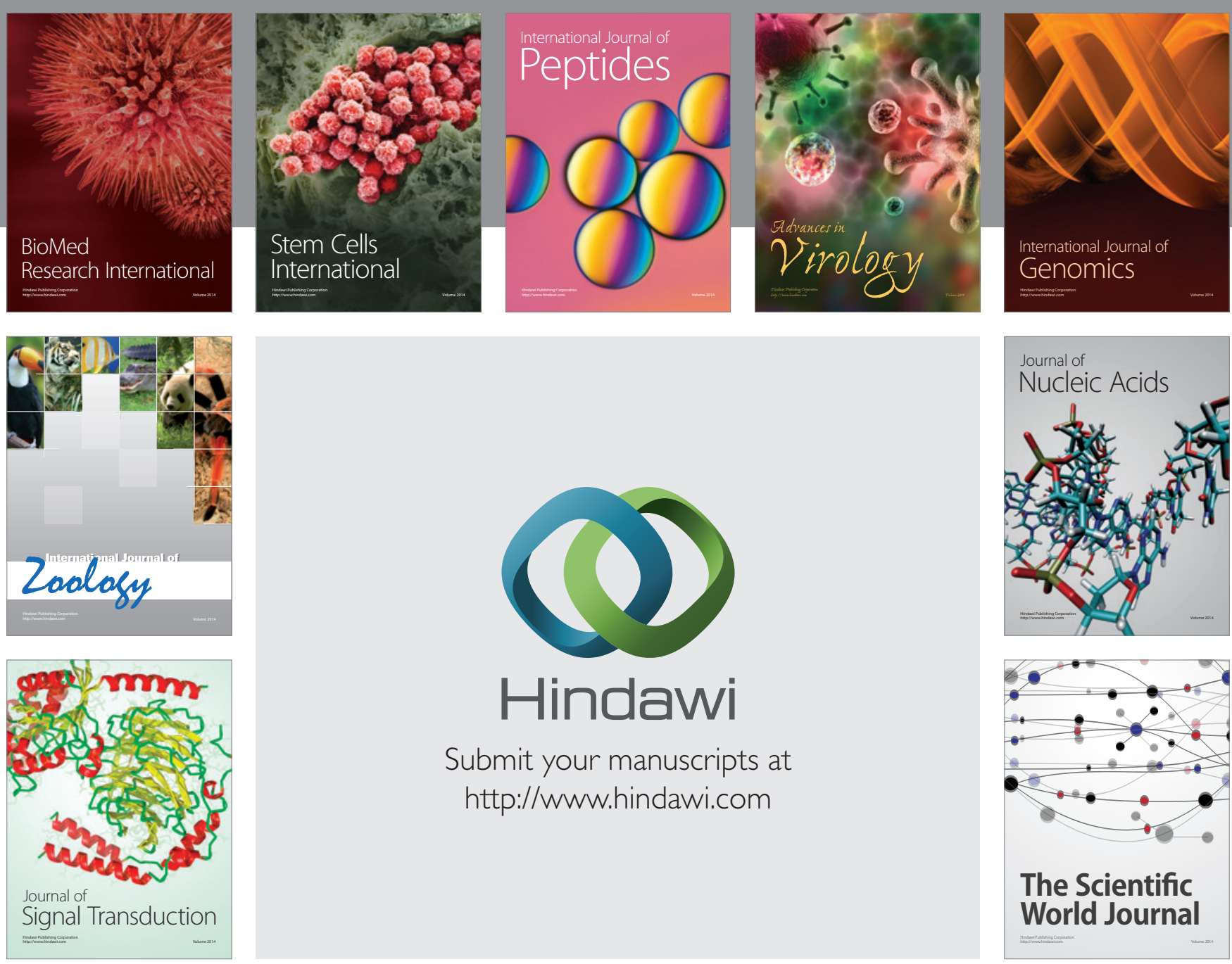

Submit your manuscripts at

http://www.hindawi.com
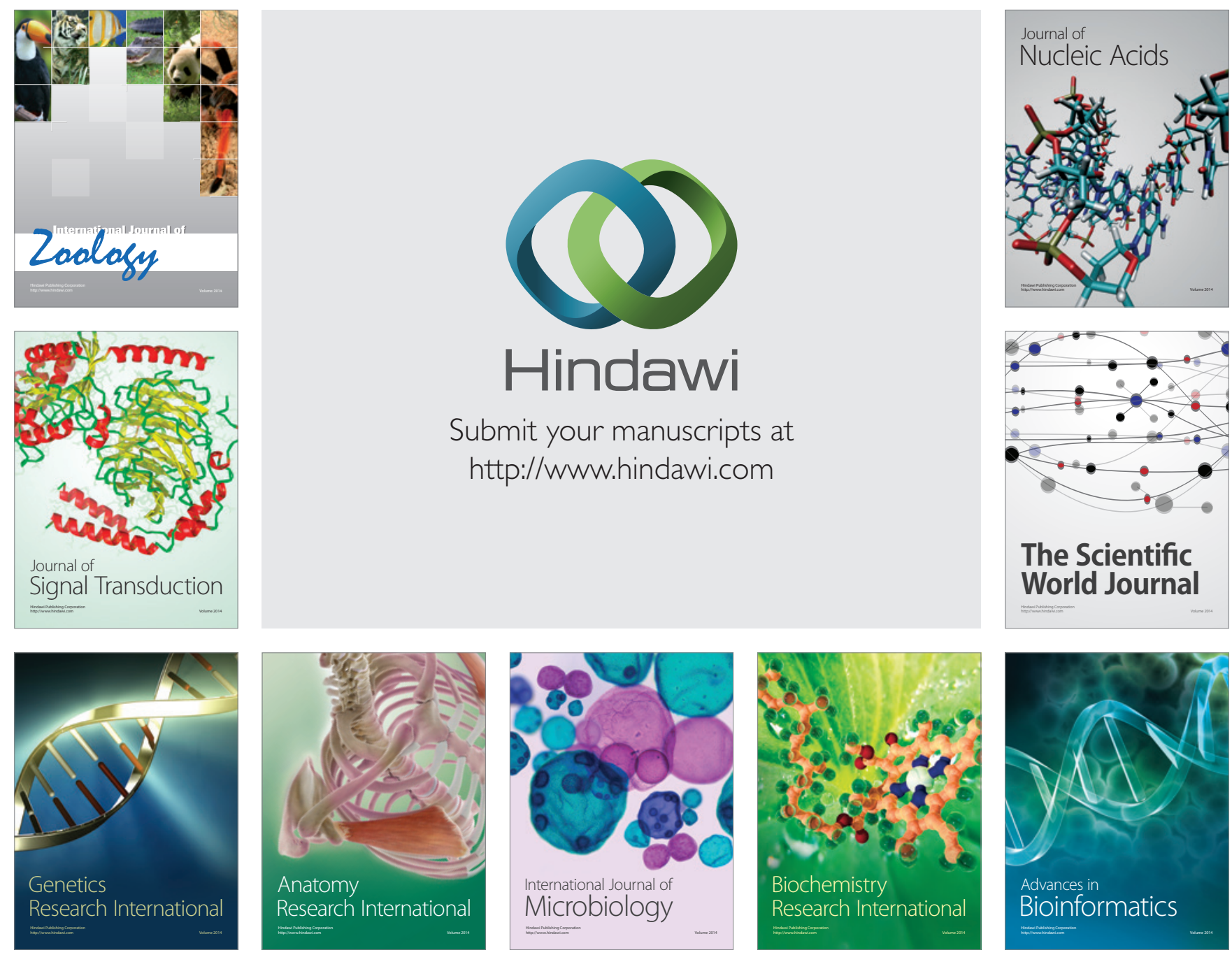

The Scientific World Journal
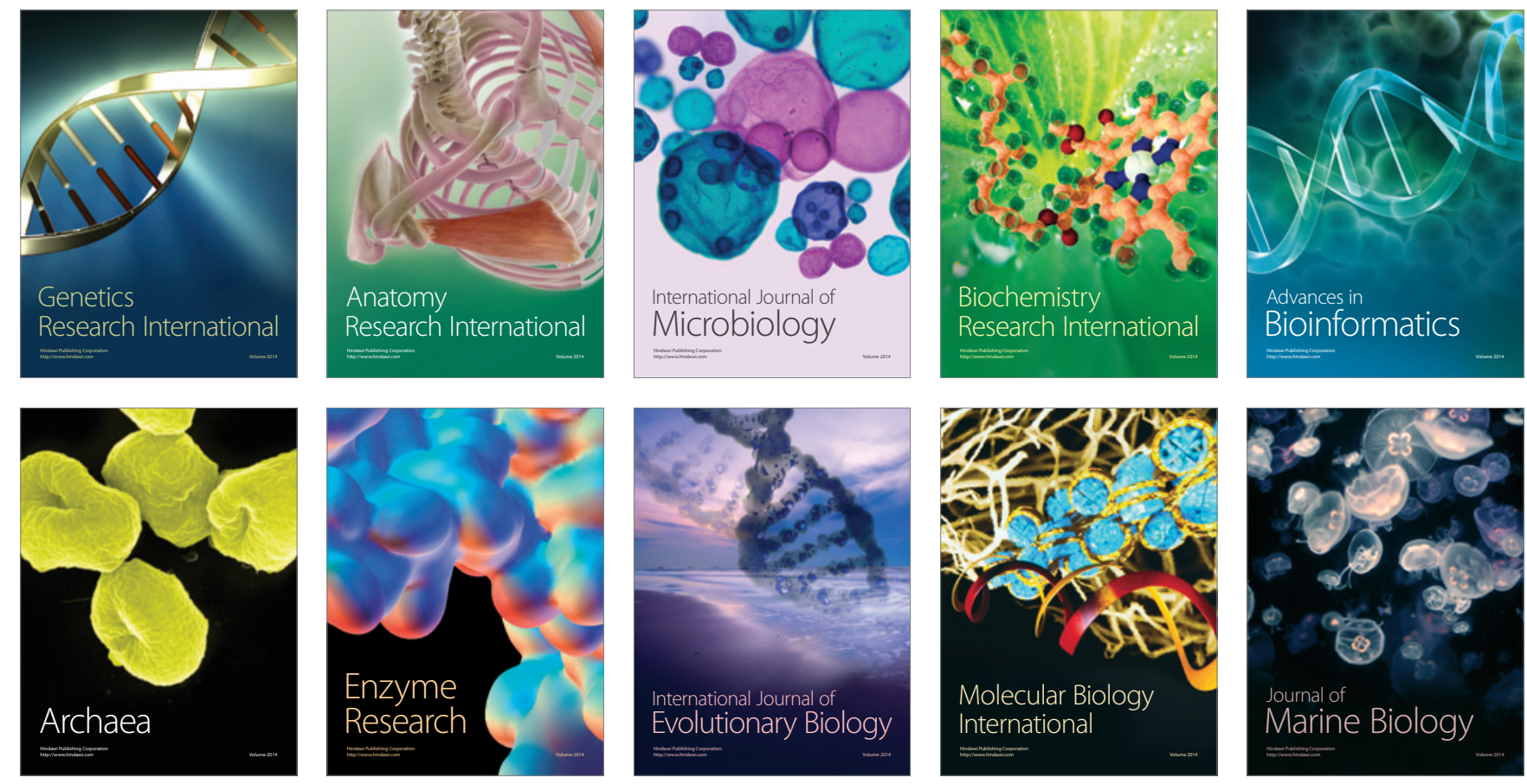